\title{
EVOLUÇÃO DO CAPITAL SOCIAL EMPREENDEDOR DOS SPIN-OFFS UNIVERSITÁRIOS
}

\author{
Cândido Borges ${ }^{1}$ \\ FACE/UFG
}

\author{
Louis Jacques Filion ${ }^{2}$ \\ HEC Montréal,
}

\begin{abstract}
RESUMO: Apesar de a literatura do campo do empreendedorismo reconhecer a evolução do capital social, ao longo do processo de criação de uma empresa, as pesquisas até aqui realizadas registraram, em geral, a estrutura da rede em certo momento e não as mudanças ocorridas nessa estrutura ao longo do tempo. Frente a esta lacuna, o objetivo deste artigo é responder a seguinte questão: como evolui o capital social empreendedor ao longo de processo de criação de um spin-off universitário? Para tanto, são aqui apresentados os resultados de uma pesquisa indutiva, exploratória e qualitativa realizada com oito casos de spin-offs universitários. O processo de criação de spin-offs é dividido em quatro etapas (iniciação, preparação, lançamento e consolidação) e os contatos da rede mobilizados pelos empreendedores são analisados em cada uma destas etapas. Os resultados indicam que na etapa iniciação, o capital social mobilizado é essencialmente tecnológico e que ele progride e se diversifica até a etapa de consolidação, onde ocorre o crescimento da mobilização da rede de negócios. O artigo mostra a importância dos empreendedores anteciparem a mobilização dos contatos de negócio e a necessidade das universidades e suas incubadoras favorecerem esse tipo de relação.
\end{abstract}

Palavras-chave: Spin-offs, capital social, empreendedorismo.

\section{ABSTRACT}

Although the literature of the field of entrepreneurship recognize the evolution of the social capital along the process of new venture creation creating, the researches conducted so far analyzed mainly the structure of the network at certain moment and not the changes occurred in this structure over the time. The evolution of the network at different times of development of a new company is still a phenomenon poorly studied. Face to this gap, this study aims at answering the following question: how entrepreneurial social capital evolves over the process of creating a university spinoff? To that purpose, here are presented the results of an inductive, exploratory and qualitative research carried out with eight cases of university spin-offs. The process of creating spin-offs is divided into four stages (initiation, preparation, launch and consolidation) and the contacts mobilized by the entrepreneurs are analyzed in each of these steps.

Keywords: Spin-offs, social capital, entrepreneurship.

Professor Adjunto - Endereço: Caixa Postal 131, 74001-970 - Goiânia-GO, Brasil candidoborges@gmail.com PhD em Administração, HEC Montreal.

${ }^{2}$ Rogers J.A. Bombardier, Chair of Entrepreneurship, HEC Montréal, The Montréal Business School Professor Titular 3000 Chemin de la Côte Sainte-Catherine, Montréal, PQ, Canada, H3T 2A7 louisjacques.filion@hec.ca PhD em Empreendedorismo, Lancaster University. 


\section{INTRODUÇÃO}

Um dos fatores de sucesso na criação de uma nova empresa é o capital social do empreendedor (JULIEN, 2000; DAVIDSSON; HONIG, 2003; NEERGAARD; MADSEN, 2004; VALE; GUIMARAES, 2010). O capital social designa a rede de relações do empreendedor e os recursos que ele pode mobilizar graças a essa rede (BOURDIEU, 1980; NAHAPIET; GHOSHAL, 1998; LIN, 2001b). O capital social permite ao empreendedor obter recursos que, de outra forma, não the seriam acessíveis ou the seriam, mas de uma forma mais onerosa em termos de tempo, de custos ou de esforços para adquiri-los (BOURDIEU, 1986; BURT, 1992; GRANOVETTER, 2000; LIN, 2001a; WITT, 2004).

Assim como a criação de uma nova empresa é um processo dinâmico, que compreende a realização de várias atividades e que necessita de recursos variados ao longo de seu desenvolvimento (REYNOLDS; MILLER, 1992; BRUYAT; JULIEN, 2001; FILION, 2001), a estrutura do capital social que um empreendedor mobiliza ao longo deste processo também o é - ela evolui e se modifica ao longo do tempo (JOHANNISSON, 1998; HANSEN, 2000; GREVE; JANE, 2003; LECHNER; DOWLING, 2003; SCHUTJENS; STAM, 2003). As necessidades em recursos e em apoio do empreendedor mudam ao longo do processo de criação; em consequência, a rede de relacionamento que veicula estes recursos muda também. Novos contatos são mobilizados enquanto outros deixam de ser utilizados.

Perez e Sanchez (2003) afirmam que, no caso dos spin-offs universitários, a mudança na estrutura da rede mobilizada entre o início e o fim do processo de criação é ainda mais significativa que no caso dos empreendedores tradicionais, pois uma rede de relações essencialmente de cunho cientifico deve ser parcialmente completada por uma rede de negócios.

Apesar de a literatura do campo do empreendedorismo reconhecer a evolução do capital social ao longo do processo de criação de uma empresa, as pesquisas até aqui realizadas analisaram essencialmente a estrutura da rede do empreendedor de forma estática (NICOLAOU; BIRLEY, 2003; NEERGAARD; MADSEN, 2004). Elas registraram, em geral, a estrutura da rede em certo momento e não as mudanças ocorridas nessa estrutura ao longo do tempo. A evolução da rede nos diferentes momentos do desenvolvimento de uma nova empresa é um 
fenômeno ainda pouco estudado (COOPER, 2002; BATJARGAL, 2003; HOANG; ANTONCIC, 2003; LECHNER; DOWLING, 2003; LIAO; WELSCH, 2003).

Frente a esta lacuna, o objetivo deste artigo é responder a seguinte questão: como evolui o capital social empreendedor ao longo de processo de criação de um spin-off universitário? Capital social empreendedor designa neste texto os contatos que os empreendedores mobilizam para realizar a criação de uma empresa (KIM; ALDRICH, 2005). Ele não inclui todos os contatos da rede dos empreendedores, mas apenas aqueles mobilizados em beneficio do novo negócio.

Para responder essa questão de pesquisa foi realizada uma pesquisa exploratória com oito casos de spin-offs universitários. O processo de criação de spin-offs foi dividido em quatro etapas (iniciação, preparação, lançamento e consolidação) e os contatos mobilizados pelos empreendedores, em cada uma destas etapas, foram analisados. Os resultados desta pesquisa são apresentados na quarta seção deste artigo. Antes, a segunda seção apresentará o referencial teórico utilizado para definir e delimitar a pesquisa; e a terceira seção descreverá a metodologia utilizada para realizá-la.

\section{REFERENCIAL TEÓRICO}

As duas primeiras partes desta seção apresentam os principais conceitos que formam a base teórica da pesquisa realizada: (i) os spin-offs universitários e seu processo de criação e (ii) o capital social empreendedor. A terceira e última parte apresenta o quadro de análise criado com base na interseção destes dois conceitos.

\subsection{OS SPIN-OFFS UNIVERSITÁRIOS}

O termo "spin-off" origina-se da língua inglesa e é usado tanto para se referir a um resultado como ao processo que gera esse resultado. Como processo, ele faz alusão ao fato de uma nova empresa, seus empreendedores, a tecnologia utilizada na nova empresa ou todos estes deixarem ou serem lançados para fora de uma organização já existente, também chamada de organização-mãe. $O$ resultado deste processo é uma nova empresa criada, o spin-off (FILION, LUC; FORTIN, 2003; MEYER, 2003; PIRNAY, SURLEMONT; NLEMVO, 2003). 
Spin-off universitário, também conhecido por spin-off acadêmico, é uma das categorias de spin-offs tecnológicos. Os spin-offs tecnológicos são empresas de base tecnológicas criadas por meio de um processo de spin-off. Esse tipo de spin-off tem, em geral, como organização-mãe uma outra empresa tecnológica, laboratórios de pesquisa ou universidades. Spin-offs universitários são gerados por esse último tipo de organização-mãe, as universidades e demais tipos de instituições de ensino superior (PIRNAY, SURLEMONT; NLEMVO, 2003; SHANE, 2004).

A organização-mãe, junto com o empreendedor e a tecnologia compõem os três principais componentes que atuam na geração de spin-off universitário (BORGES, 2010). Essa organização-mãe é normalmente a origem do empreendedor e da tecnologia que servirá de base para a criação da nova empresa. Além de ser a origem dos empreendedores e da tecnologia, as universidades podem apoiar 0 processo de criação da nova empresa. Existem várias formas de apoio: acesso aos laboratórios, registro de patentes, consultorias e treinamentos em gestão, espaços para instalação das empresas iniciantes, assessoria na captação de recursos financeiros e acesso à rede de contatos da universidade (OCDE, 2001; KADJIYOUALEU; FILION, 2002; DI GREGORIO; SHANE, 2003; GRIMALDI; GRANDI, 2005). No Brasil, um dos principais instrumentos de suporte das universidades à geração de spin-offs são as incubadoras de empresas, onde se concentram vários serviços de apoio (VERSIANI; GUIMARÃES, 2003, 2006; WOLFFENBÜTTEL, FRACASSO; BIGNETTI, 2004). A estrutura de apoio oferecido pelas universidades, especialmente pelas incubadoras nelas instaladas, varia muito. Algumas instituições oferecem apenas serviços básicos, enquanto outras oferecem apoio mais bem estruturado, que inclui acompanhamento por um longo período e ajuda na comercialização e financiamento do novo negócio (CLARYSSE. et al. 2005).

Sobre os empreendedores de um spin-off, Pirnay, Surlemont e Nlemvo (2003) afirmam que eles podem ser divididos em duas categorias principais - estudantes e acadêmicos. A primeira categoria é formada por estudantes de graduação ou pósgraduação da universidade e a segunda por professores e pesquisadores da instituição. Mas é possível que o spin-off seja criado também por um empreendedor externo (RADOSEVICH, 1995). Neste último caso, a universidade faz a transferência da tecnologia ou oferece apoio ao processo de criação da nova empresa, mas o 
empreendedor vem do exterior - não é nem estudante e nem professor da instituição.

O empreendedor externo (também chamado de surrogate ou substituto) pode criar a nova empresa só ou em parceria com pesquisadores, professores ou alunos da universidade (FRANKLIN; WRIGHT, 2000). Não é raro que os spin-offs sejam criados por equipes de empreendedores (COOPER; DAILLY, 1997; NEERGAARD, 2005), sendo possível encontrar, na mesma equipe, as três diferentes categorias de empreendedor - professores, estudantes e externos (NICOLAOU; BIRLEY, 2003).

Quanto à tecnologia transferida pela universidade aos spin-offs, Pirnay, Surlemont e Nlemvo (2003) afirmam existir dois tipos principais de tecnologias ou conhecimentos tecnológicos que são aproveitados pelos spin-offs: tácitos e codificados. Os conhecimentos tácitos são mais associados aos indivíduos, que os acumulam na universidade, participando das atividades universitárias, como aulas e pesquisas. Por outro lado, os codificados podem pertencer, ao menos em parte, à universidade, na forma de uma patente. Em geral, os spin-offs universitários são criados principalmente utilizando conhecimentos tecnológicos tácitos (PIRNAY, SURLEMONT; NLEMVO, 2003).

Apesar de Pirnay, Surlemont e Nlemvo (2003) considerarem apenas tecnologias apreendidas ou desenvolvidas na universidade, Luc, Savary e Filion (2003) ressaltam que em certos casos de spin-offs a tecnologia pode-se originar de uma organização outra que a universidade ou ainda ser híbrida, onde o spin-off utiliza a tecnologia desenvolvida fora da universidade, mas que agrega conhecimentos tecnológicos da própria universidade.

O quadro 1 sintetiza os três componentes de base que atuam na geração de um spin-off universitário, ressaltando seus tipos e seu papel. 
Quadro 1 - Identificação e papel dos principais componentes dos spins-offs universitários

\begin{tabular}{|c|c|c|}
\hline Componente & Tipos & Papel \\
\hline Universidade & $\begin{array}{c}\text { Variação nos serviços e na estrutura } \\
\text { de serviços ofertados aos } \\
\text { empreendedores. }\end{array}$ & $\begin{array}{c}\text { A organização-mãe é a origem dos } \\
\text { empreendedores ou da tecnologia. } \\
\text { Além disso, ela apoia o processo de } \\
\text { criação da nova empresa. }\end{array}$ \\
\hline Empreendedor & $\begin{array}{c}\text { Professor/pesquisador } \\
\text { Estudante } \\
\text { Externo }\end{array}$ & $\begin{array}{c}\text { Criador da empresa, só ou em } \\
\text { equipe. }\end{array}$ \\
\hline Tecnologia & $\begin{array}{c}\text { Tácita (mais associada aos } \\
\text { indivíduos) }\end{array}$ & $\begin{array}{c}\text { A tecnologia é a base dos produtos } \\
\text { e serviços desenvolvidos pelo spin- } \\
\text { off. }\end{array}$ \\
& $\begin{array}{c}\text { Codificada (resultados de pesquisa } \\
\text { que normalmente se transformam em } \\
\text { patentes e pertencem, ao menos em } \\
\text { parte, à universidade) }\end{array}$ & \\
\hline
\end{tabular}

Fonte: Adaptado de Borges (2010), Quadro 3, p. 14.

\subsection{PROCESSO DE CRIAÇÃO DE SPIN-OFFS UNIVERSITÁRIO}

O processo de criação de um spin-off é aqui considerado como o conjunto de atividades que o empreendedor realiza para conceber, organizar e lançar a nova empresa tecnológica (BORGES, FILION; SIMARD, 2010). Entre as atividades deste processo mais citadas na literatura, encontram-se a identificação de uma oportunidade de negócios, a reflexão e desenvolvimento da ideia de negócios, a redação do plano de negócios, a mobilização de recursos financeiros, a constituição da equipe empreendedora, o desenvolvimento do produto, a contratação de colaboradores e a comercialização de produtos (VESPER, 1990; BHAVE, 1994; CARTER, GARTNER; REYNOLDS, 1996).

Alguns autores retratam o processo de criação por etapas. Cinco exemplos de modelos de processo de criação de empresas tecnológicas estruturado em etapas são mostrados no quadro 2. A apresentação do processo de criação por etapas visa facilitar a compreensão e o estudo do fenômeno e ilustra a trajetória mais comum, não representando necessariamente que seja esse o único caminho que as empresas nascentes podem percorrer (TESFAYE, 1997; CLARYSSE e MORAY, 2004; VOHORA, WRIGHT; LOCKET, 2004; BORGES, FILION; SIMARD, 2010). 
Quadro 2 - Quatro modelos de criação de empresas tecnológicas

\begin{tabular}{|l|c|c|c|c|c|}
\hline \multicolumn{1}{|c|}{ Autores } & \multicolumn{5}{c|}{ Etapas do processo de criação } \\
\hline $\begin{array}{l}\text { Borges, Filion, } \\
\text { Simard (2010) }\end{array}$ & Iniciação & Preparação & Lançamento & Consolidação & \\
\hline $\begin{array}{l}\text { Clarysse e Moray } \\
\text { (2004) }\end{array}$ & Ideia & $\begin{array}{c}\text { Pré- } \\
\text { lançamento }\end{array}$ & Lançamento & Pós-lançamento & \\
\hline $\begin{array}{l}\text { Ndonzuau, Pirnay, } \\
\text { Surlemont (2002) }\end{array}$ & $\begin{array}{c}\text { Gerar ideias } \\
\text { de negócio } \\
\text { baseadas em } \\
\text { resultados de } \\
\text { pesquisas }\end{array}$ & $\begin{array}{c}\text { Fazer o } \\
\text { projeto de uma } \\
\text { nova empresa }\end{array}$ & $\begin{array}{c}\text { Lançar a nova } \\
\text { empresa }\end{array}$ & $\begin{array}{c}\text { Aumentar a } \\
\text { criação de valor } \\
\text { econômico }\end{array}$ & \\
\hline Tesfaye (1997) & Iniciação & Aclimatação & Consolidação & Lançamento & Infância \\
\hline $\begin{array}{l}\text { Vohora, Wright, } \\
\text { Lockett (2004) }\end{array}$ & Pesquisa & $\begin{array}{c}\text { Modulação da } \\
\text { oportunidade }\end{array}$ & $\begin{array}{c}\text { Pré- } \\
\text { organização }\end{array}$ & Reorientação & $\begin{array}{c}\text { Retorno } \\
\text { sustentável }\end{array}$ \\
\hline
\end{tabular}

Fonte: Preparado pelos autores.

Borges, Filion e Simard (2010) incluem em seu modelo as atividades que são realizadas em cada uma das etapas do processo de criação de empresas tecnológicas. Este modelo, com adaptações, é mostrado no quadro 3. As adaptações feitas são a inclusão de duas atividades: (i) compreensão do empreendedorismo (na etapa iniciação) e (ii) aprendizagem da gestão (na etapa preparação).

Essas atividades foram incluídas visando adaptar o modelo a uma particularidade dos spin-offs universitários, não considerada por Borges, Filion e Simard (2010). Os spin-offs universitários apresentam a particularidade, frente às demais empresas tecnológicas, de normalmente contar com algum apoio da universidade. Uma das formas de apoio, como indicado anteriormente, são as incubadoras de empresas (GRIMALDI; GRANDI, 2005). Os empreendedores têm acesso, em cursos de empreendedorismo proporcionados pela universidade ou pela própria incubadora, às noções iniciais de empreendedorismo e de gestão empresarial e seguem, na incubadora, um processo estruturado onde, além destes cursos, precisam fazer também um plano de negócios (VERSIANI; GUIMARÃES, 2003; 2006; WOLFFENBÜTTEL, FRACASSO; BIGNETTI, 2004). 
Quadro 3 - Etapas e atividades do processo de criação de spin-offs universitários

\begin{tabular}{|c|c|c|c|c|}
\hline $\begin{array}{l}\mathscr{9} \\
\mathbb{2} \\
\frac{2}{9}\end{array}$ & Iniciação & Preparação & Lançamento & Consolidação \\
\hline 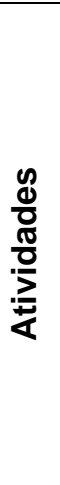 & $\begin{array}{l}\text { 1. Identificação da } \\
\text { oportunidade de } \\
\text { negócio. } \\
\text { 2. Reflexão e } \\
\text { desenvolvimento } \\
\text { da ideia de } \\
\text { negócio. } \\
\text { 3. Compreensão do } \\
\text { empreendedoris } \\
\text { mo. } \\
\text { 4. Decisão de criar } \\
\text { a empresa. }\end{array}$ & $\begin{array}{l}\text { 1. Aprendizagem da } \\
\text { gestão } \\
\text { 2. Redação do } \\
\text { plano de } \\
\text { negócios. } \\
\text { 3. Mobilização de } \\
\text { recursos } \\
\text { financeiros. } \\
\text { 4. Constituição da } \\
\text { equipe } \\
\text { empreendedora. }\end{array}$ & $\begin{array}{l}\text { 1. Constituição legal } \\
\text { da empresa. } \\
\text { 2. Desenvolvimento } \\
\text { do primeiro } \\
\text { produto ou } \\
\text { serviço. } \\
\text { 3. Contratação de } \\
\text { colaboradores. } \\
\text { 4. Comercialização } \\
\text { e venda. }\end{array}$ & $\begin{array}{l}\text { 1. Novas rodadas } \\
\text { de financiamento. } \\
\text { 2. Promoção e } \\
\text { comercialização. } \\
\text { 3. Operação e } \\
\text { produção. } \\
\text { 4. Gestão da nova } \\
\text { empresa. }\end{array}$ \\
\hline
\end{tabular}

Fonte : Adaptado de Borges, Filion e Simard (2010).

\subsection{CAPITAL SOCIAL EMPREENDEDOR}

Adler e Kwon (2002) indicam duas perspectivas principais nas pesquisas que utilizam o conceito de capital social: (i) perspectiva externa, quando o foco do estudo são as relações externas de um ator e (ii) perspectiva interna, quando o foco são as relações internas de um grupo ou comunidade. Este artigo utiliza a primeira perspectiva. O seu foco são as relações externas dos empreendedores que criam um spin-off universitário.

Lin (2001a e 2001b) observa que entre os contatos de um ator, apenas alguns podem servir para um fim especifico e um número ainda menor são efetivamente mobilizados para este fim. Estes últimos são chamados de contatos mobilizados ou capital social mobilizado. Na pesquisa objeto do presente artigo, o fim especifico é a criação de uma empresa. $O$ interesse é nos contatos mobilizados durante o processo de criação de uma empresa e em prol do mesmo processo. Neste sentido, - capital social empreendedor não inclui todos os contatos da rede dos empreendedores, mas apenas aqueles que eles mobilizam em beneficio do novo negócio (KIM; ALDRICH, 2005). Serão apresentados, em seguida, dois aspectos do capital social empreendedor: (i) as características do capital social e (ii) sua evolução ao longo do tempo. 


\subsection{AS CARACTERÍSTICAS DO CAPITAL SOCIAL EMPREENDEDOR}

Em estudo sobre uma rede egocêntrica, como neste artigo, as relações analisadas são as de um ator focal com outros atores (LAZEGA, 1998; LEMIEUX; OUIMET, 2004), que serão chamados de contatos. A literatura utiliza também os termos ego e alters para designar 0 ator focal e os contatos de uma rede egocêntrica (SCOTT, 1991; WASSERMAN; FAUST, 1997; LAZEGA, 1998). Antes de passar a discutir quem são os contatos do capital social empreendedor, é importante uma precisão sobre $o$ ator focal.

Quando se trata de um fenômeno de criação de empresas, deve-se considerar que o ator focal é o empreendedor ou a empresa nascente? Nas pesquisas do campo do empreendedorismo, que investigam o capital social, o ator focal é geralmente tratado indistintamente como sendo o empreendedor ou a empresa nascente. Isso se explica pelo fato que, normalmente, em uma empresa nascente são os empreendedores que realizam a maior parte das atividades, inclusive as relações com os contatos da nova empresa (ALDRICH, 1999).

Em consequência, as pesquisas tratam o empreendedor (ou os empreendedores) e a empresa nascente como uma única unidade de análise (HOANG; ANTONCIC, 2003), como foi o caso, por exemplo, dos estudos de Hite (2003), de Johannisson (1998) e de Johannisson, Ramirez-Pasillas e Karlsson (2002). Johannisson (1998, p. 300) justifica este procedimento dizendo que "since the entrepreneur epitomizes the small firm and its physical and human resources, the individual and the organization as unit of analysis coincide". Assim como estes autores, neste artigo, o empreendedor (ou empreendedores) e a empresa nascente serão tratados como único ator focal.

\subsection{OS CONTATOS DA REDE}

Um contato é um ator com quem o ator focal tem uma relação direta (LEMIEUX; OUIMET, 2004). Um contato pode ser um individuo ou uma organização. O quadro 4 indica os principais contatos dos empreendedores tecnológicos. 
Quadro 4 - Principais contatos dos empreendedores tecnológicos

$\begin{array}{ll}\text { - } & \text { Amigos } \\ \text { - } \text { Universidade } \\ \text { - } \text { Membros da universidade } \\ \text { - Professores e } \\ \text { - } \text { Pesquisadores } \\ \text { - Parcitutos de pesquisa } \\ \text { - Paros }\end{array}$

- Clientes

- Fornecedores

- Bancos

- Capitalistas de risco

- Outros atores do meio financeiro

- Consultores

- Contadores

Fontes : Birley (1985), Aldrich e Zimmer (1986), Dubini e Aldrich (1991), Hill, McGowan e Drummond (1999), Julien (2000), Pirnay (2001) e Maculan e outros (2002).

Os contatos podem ser classificados ou agrupados segundo o papel que eles desempenham ou os recursos que eles disponibilizam para os empreendedores (JULIEN, 2000; JOHANNISSON, RAMIREZ-PASILLAS; KARLSSON, 2002; LECHNER; DOWLING, 2003). Por exemplo, a rede de apoio moral (normalmente família e amigos), a rede tecnológica (pesquisadores e universidade, por exemplo), a rede de suporte (organizações de apoio ao empreendedorismo), a rede de negócios (clientes, fornecedores). Um mesmo contato pode ser, ao mesmo tempo, amigo e cliente, ou membro da família e investidor. Dessa forma, podem existir contatos que desempenham dois papéis no capital social empreendedor (JOHANNISSON, 1996; UZZI, 1996; HITE, 2003). É o caso de um amigo pesquisador que proporciona ao empreendedor tecnológico apoio moral e informações tecnológicas. Esse tipo de contato, que desempenha papéis diferentes ou proporciona recursos variados ao empreendedor é chamado de multiplex (KIM; ALDRICH, 2005).

\subsection{A EVOLUÇÃO DA REDE AO LONGO DO TEMPO}

Em pesquisa realizada nos Estados Unidos, com 52 novas empresas de todos os setores econômicos, Hansen (2000) verificou o número de contatos mobilizados em cada uma das etapas do processo de criação. $O$ autor dividiu 0 processo em quatro etapas, denominadas etapas 1, 2, 3 e 4 . Os resultados da pesquisa indicam um crescente número de contatos mobilizados: etapa 1 (7 contatos), etapa 2 ( 8 contatos), etapa 3 ( 11 contatos) e etapa 4 (12 contatos).

Ao longo do tempo, além do crescimento do número de contatos mobilizados, - capital social empreendedor tende também a mudar no que diz respeito à diversidade dos contatos que compõem a rede. Perez e Sanchez (2003), na Espanha, e Johannisson (1998), na Suécia, realizaram pesquisas com spin-offs 
universitários e concluíram que uma rede, que se inicia formada principalmente por contatos científicos, torna-se uma rede composta cada vez mais por contatos de negócios.

Essa diversificação é importante porque o aumento do número de contatos na rede por si só não garante mais benefícios ao ator focal. Esse aumento de benefícios tende a acontecer apenas quando ocorre também a diversificação nas características dos contatos (ALDRICH, ROSEN; WOODWARD, 1987; ALDRICH; CARTER, 2004). A diversificação pode ocorrer de diferentes formas: nas características demográficas dos contatos, nos recursos que eles disponibilizam e nas redes a que estes contatos pertencem.

\subsection{QUADRO DE ANÁLISE}

Sendo o objetivo da pesquisa compreender como o capital social empreendedor evolui ao longo de processo de criação de um spin-off universitário, é importante conhecer o capital social mobilizado em cada uma das etapas do processo de criação. Nesse sentido, adotou-se um quadro de análise que coloca em evidência dois aspectos: (i) as etapas do processo de criação do spin-off e (ii) o capital social empreendedor em cada uma das etapas.

O quadro de análise é representado na figura 1. As redes no interior de cada uma das etapas representam o capital social empreendedor. São os contatos que o empreendedor mobiliza para concretizar as atividades da etapa correspondente. Utilizou-se o modelo de Borges, Filion e Simard (2010) como referência para definir as etapas e as atividades do processo de criação. Este modelo foi mostrado anteriormente, no quadro 3. 
Figura 1 - Quadro de análise.

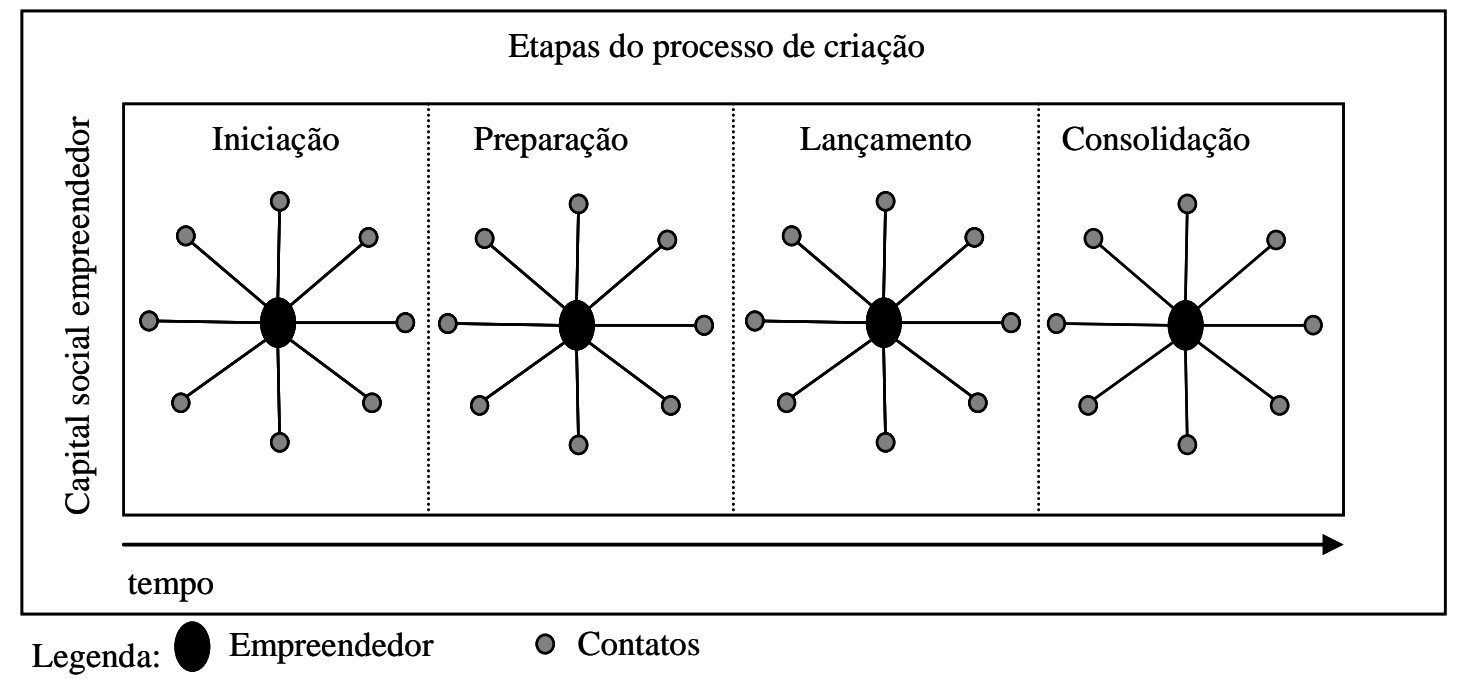

\section{METODOLOGIA}

A pesquisa foi exploratória e qualitativa. Oito casos de spin-offs universitários foram analisados. O número de oito casos é resultado da saturação teórica (EISENHARDT, 1989; STRAUSS; CORBIN, 1998) durante a fase de codificação e análise dos dados. A tabela 1 abaixo resume os procedimentos metodológicos adotados na pesquisa.

Tabela 1 - Síntese dos procedimentos metodológicos

\begin{tabular}{|c|c|}
\hline Método de pesquisa & - Análise de múltiplos casos (EISENHARDT, 1989; YIN, 2003) \\
\hline Número de casos & - Oito casos \\
\hline $\begin{array}{l}\text { Critérios de escolha } \\
\text { dos casos }\end{array}$ & $\begin{array}{l}\text { - Spin-offs universitários com dois a quatro anos de vida. } \\
\text { - Variação máxima (PATTON, 2002) nos componentes de base dos spin- } \\
\text { offs } \\
\text { (empreendedor, organização-mãe e tecnologia). }\end{array}$ \\
\hline Coleta de dados & $\begin{array}{l}\text { - Entrevistas semiestruturadas, notas de pesquisa e dados secundários } \\
\text { - } 35 \text { entrevistas ( } 2 \mathrm{~h} \text { em média): } 22 \text { com empreendedores/13 com } \\
\text { gerentes e } \\
\text { outros profissionais de incubadoras } \\
\text { - Guia de entrevistas inspirado no gerador de recursos (VAN DER GAAG } \\
\text { e SNIJDERS, 2004, 2005) }\end{array}$ \\
\hline $\begin{array}{l}\text { Análise e interpretação } \\
\text { dos dados }\end{array}$ & $\begin{array}{l}\text { - Transcrição das entrevistas } \\
\text { - Codificação e análise das entrevistas com ajuda do NVivo } 2.0 \\
\text { - Ficha de descrição de cada caso } \\
\text { - Tabelas analíticas } \\
\text { - Comparação intra e entre casos } \\
\text { - Comparação com a literatura }\end{array}$ \\
\hline
\end{tabular}

Fonte: Elaborado pelos autores.

Os oito casos analisados são de diferentes setores tecnológicos e regiões brasileiras. Trata-se de empresas fundadas entre 2000 e 2003. A tabela 2 apresenta 
informações complementares sobre os casos escolhidos. Por razões de confidencialidade, os nomes das empresas são fictícios.

Tabela 2 - Apresentação dos casos

\begin{tabular}{|l|l|l|l|c|c|}
\hline Empresa & Fundação & \multicolumn{1}{|c|}{ Atividade } & \multicolumn{1}{|c|}{ Cidade } & $\begin{array}{c}\mathbf{N}^{\circ} \text { de } \\
\text { Empreendedores }\end{array}$ & $\begin{array}{c}\mathbf{N}^{\circ} \text { de } \\
\text { Colaboradores }\end{array}$ \\
\hline Aprendiz & 2003 & $\begin{array}{l}\text { Softwares de } \\
\text { comunicação }\end{array}$ & Blumenau & 2 & 3 \\
\hline Freeway & 2003 & $\begin{array}{l}\text { Softwares e } \\
\text { treinamento }\end{array}$ & Brasília & 4 & 13 \\
\hline Imagem & 2003 & Geoprocessamento & Goiânia & 2 & 0 \\
\hline Quimitech & 2002 & $\begin{array}{l}\text { Sistemas automáticos } \\
\text { de análise química }\end{array}$ & Campinas & 4 & 3 \\
\hline Games & 2000 & Jogos eletrônicos & Recife & 4 & 6 \\
\hline Sensores & 2003 & Sensores óticos & $\begin{array}{l}\text { Rio de } \\
\text { Janeiro }\end{array}$ & 5 & 8 \\
\hline Visitech & 2003 & $\begin{array}{l}\text { Sistemas de visão } \\
\text { artificial }\end{array}$ & $\begin{array}{l}\text { São } \\
\text { Paulo }\end{array}$ & 2 & 2 \\
\hline Webdesign & 2002 & Sites Internet & Curitiba & 3 & 85 \\
\hline
\end{tabular}

Fonte: Elaborado pelos autores.

Os casos são spin-offs universitários com dois a quatro anos de vida (no momento da coleta dos dados) e foram escolhidos para garantir o que PATTON (2002) chama de variação máxima. Como critério garantidor da variação máxima utilizaram-se-se os componentes de base dos spin-offs (empreendedor, organização-mãe e tecnologia). Na variação do componente empreendedor, assegurou-se a presença, entre os casos, dos diferentes tipos de empreendedores estudantes, professores e empreendedores externos. Na variação do componente organização-mãe, os casos escolhidos eram originários de universidades e incubadoras que oferecem diferentes estruturas de pesquisa e de apoio ao empreendedorismo, indo de grandes universidades, com uma estrutura sólida e reputada, até centros de ensino com pequena estrutura em formação. Finalmente, no terceiro componente, a tecnologia, entre as tecnologias transferidas pelas universidades aos spin-offs, encontram-se casos de tecnologia tácita e de tecnologia codificadas.

Para a coleta de dados, foram realizadas 35 entrevistas semiestruturadas, que duraram entre uma e quatro horas. Das 35 entrevistas, 22 foram com empreendedores e 13 com funcionários das incubadoras (gerentes ou outros profissionais). Além das entrevistas, a coleta de dados foi completada com dados secundários (relatórios, material de publicidade, reportagens e informações na 
internet) sobre as empresas, os empreendedores, as universidades e as incubadoras. Visitas e observações em todas as empresas, as universidades e as incubadoras dos casos estudados também foram feitas.

O guia de entrevista utilizado foi inspirado no gerador de recursos (VAN DER GAAG; SNIJDERS, 2004, 2005). Como o objetivo era conhecer o capital social mobilizado em cada etapa do processo de criação do spin-off, aplicou-se a lógica do gerador de recursos às atividades do processo de criação indicadas no quadro 3, da seção 2 desse artigo. Garantiu-se assim a coleta de informações das características dos contatos mobilizados para realizar as atividades do processo de criação, o que possibilitou reconstruir em retrospectiva a história do processo de criação da empresa e a dinâmica da evolução do capital social empreendedor ao longo deste processo.

As entrevistas foram transcritas e submetidas para validação aos entrevistados. Em seguida, elas foram codificadas e analisadas com ajuda do software NVivo 2.0. O procedimento de tratamento e análise de dados usou como estratégia a decomposição temporal (LANGLEY, 1999), mais especificamente a decomposição por fases do processo (VAN DE VEM; POOLE, 1995). As fases de referências foram as etapas do processo de criação - iniciação, preparação, lançamento e consolidação. Este procedimento foi apoiado por instrumentos e técnicas de análise sugeridas por Miles e Huberman (1994): uma ficha de descrição de cada caso, tabelas analíticas e comparação intra e entre casos.

Os contatos mobilizados pelos empreendedores foram classificados pela categoria de rede as quais pertencem (veja exemplos no quadro 5). Quando um contato era multiplex (desempenhava várias funções), ele foi classificado pela sua função principal.

Quadro 5 - Classificação dos contatos

\begin{tabular}{|l|l|}
\hline \multicolumn{1}{|c|}{ Categoria } & \multicolumn{1}{c|}{ Exemplos } \\
\hline Rede tecnológica & Professores, estudantes, laboratórios \\
\hline Rede de suporte & $\begin{array}{l}\text { Empregados da incubadora, consultores, } \\
\text { SEBRAE }\end{array}$ \\
\hline Rede de financiamento & $\begin{array}{l}\text { Agências de financiamento, bancos, anjos } \\
\text { financeiros }\end{array}$ \\
\hline Rede de negócios & Clientes, fornecedores, parceiros comerciais \\
\hline Outros & Pais, outros parentes \\
\hline
\end{tabular}

Fonte: Elaborado pelos autores. 


\section{APRESENTAÇÃO E ANÁLISE DOS RESULTADOS}

Os resultados serão apresentados considerando as etapas do processo de criação do spin-off. Inicialmente, será abordado o capital social empreendedor na etapa iniciação. E, em seguida, nas etapas subsequentes - preparação, lançamento e consolidação.

\subsection{CAPITAL SOCIAL EMPREENDEDOR NA ETAPA INICIAÇÃO}

Os contatos tecnológicos são os que os empreendedores mais mobilizaram na etapa de iniciação. Como ilustra a figura 2, eles mobilizaram também, em menor grau, membros da família, contatos da rede de suporte e contatos da rede de negócios. Nos casos estudados, os contatos de financiamento não foram mobilizados nessa etapa.

Figura 2 - Ilustração do capital social empreendedor na etapa iniciação

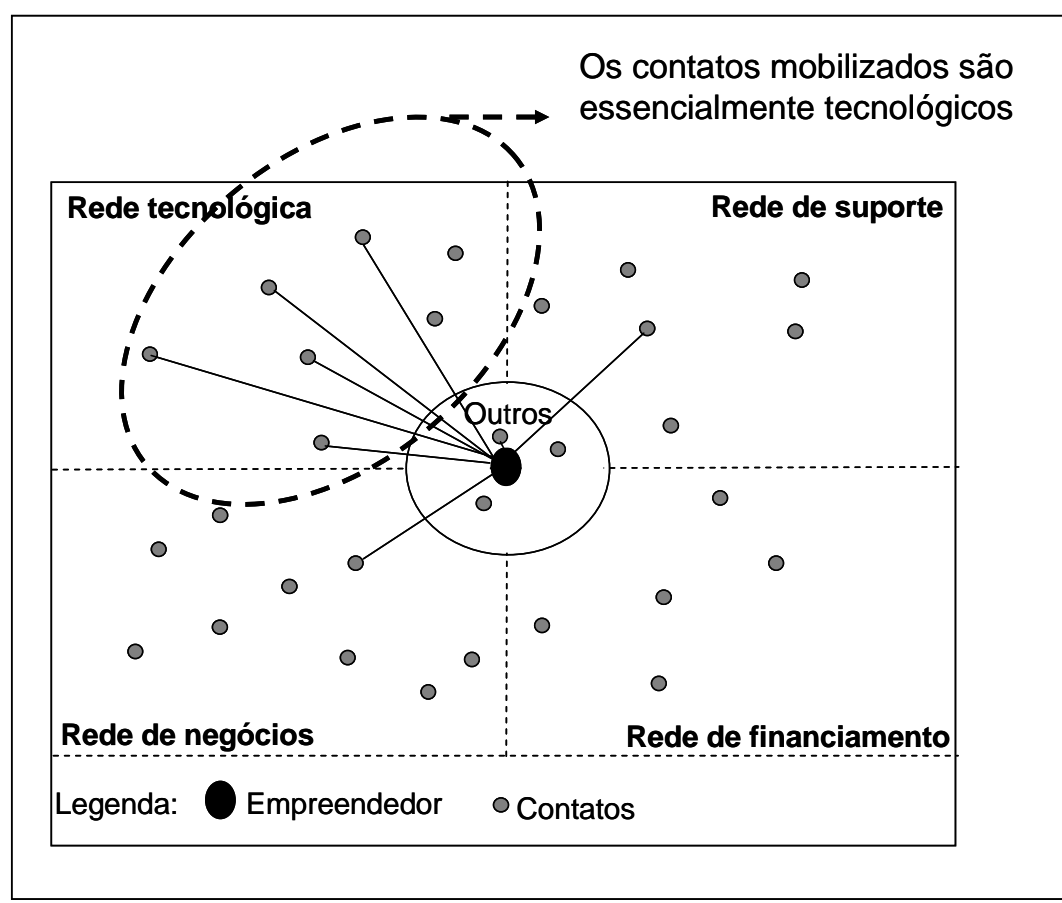

A maior presença de contatos da rede tecnológica, nessa etapa, se explica principalmente pelo fato de os empreendedores universitários (estudantes e professores) estarem imersos em um ambiente acadêmico. As pessoas com quem eles convivem no dia a dia são estudantes, professores e pesquisadores. É, em geral, da tecnologia aprendida nesse ambiente e da conversa com essas pessoas que surgem as ideias de negócio e o desenho inicial da nova empresa. No caso da 
empresa Games, por exemplo, foram professores que ajudaram os empreendedores (todos estudantes) na reflexão sobre a ideia de negócio e que os incentivaram a criar a empresa.

Existe nessa etapa uma diferença importante entre os empreendedores externos e os empreendedores da própria universidade. Os empreendedores externos mobilizam mais contatos de negócio do que fazem os empreendedores universitários. Isso se explica pelo fato de que a identificação da oportunidade de negócios e a reflexão sobre a ideia de empresa se dão, no caso dos empreendedores externos, no mercado, em contato com clientes em potencial ou com outros contatos de negócio. Já, no caso dos empreendedores universitários, esse processo, na maior parte das vezes, acontece na universidade, discutindo com pares - estudantes ou professores.

\subsection{CAPITAL SOCIAL EMPREENDEDOR NA ETAPA PREPARAÇÃO}

$\mathrm{Na}$ etapa de preparação, os empreendedores começam a estreitar as relações com a incubadora. Alguns já se instalam nela, outros começam a realizar os cursos da incubadora e a participar de seu processo de seleção. É nessa fase que os empreendedores redigem o plano de negócios, definem a equipe do projeto e começam a mobilizar os recursos financeiros para iniciar o projeto.

Ocorre aqui uma mudança importante no tipo de rede que é mobilizada. A rede tecnológica perde um pouco sua importância, e a rede de suporte ocupa o posto de rede mais presente na etapa (ver figura 3, abaixo). Em razão do que precisam (por exemplo, apreender a abrir uma empresa, a redigir um plano de negócios), os empreendedores passam a procurar mais os contatos de suporte. Os contatos de suporte mobilizados são normalmente aqueles ligados à incubadora, seja pessoal próprio, como o gerente da incubadora, seja de parceiros ou terceirizados da incubadora, como o SEBRAE ou consultores.

Um exemplo clássico do tipo de apoio dos contatos de suporte nessa etapa foi o recebido pelos empreendedores da empresa Freeway no momento de redigir o plano de negócios. Eles participaram de um treinamento sobre redação de plano de negócios na incubadora e ainda contaram com a ajuda de seus consultores durante sua redação. 
Figura 3 - Ilustração do capital social empreendedor na etapa preparação

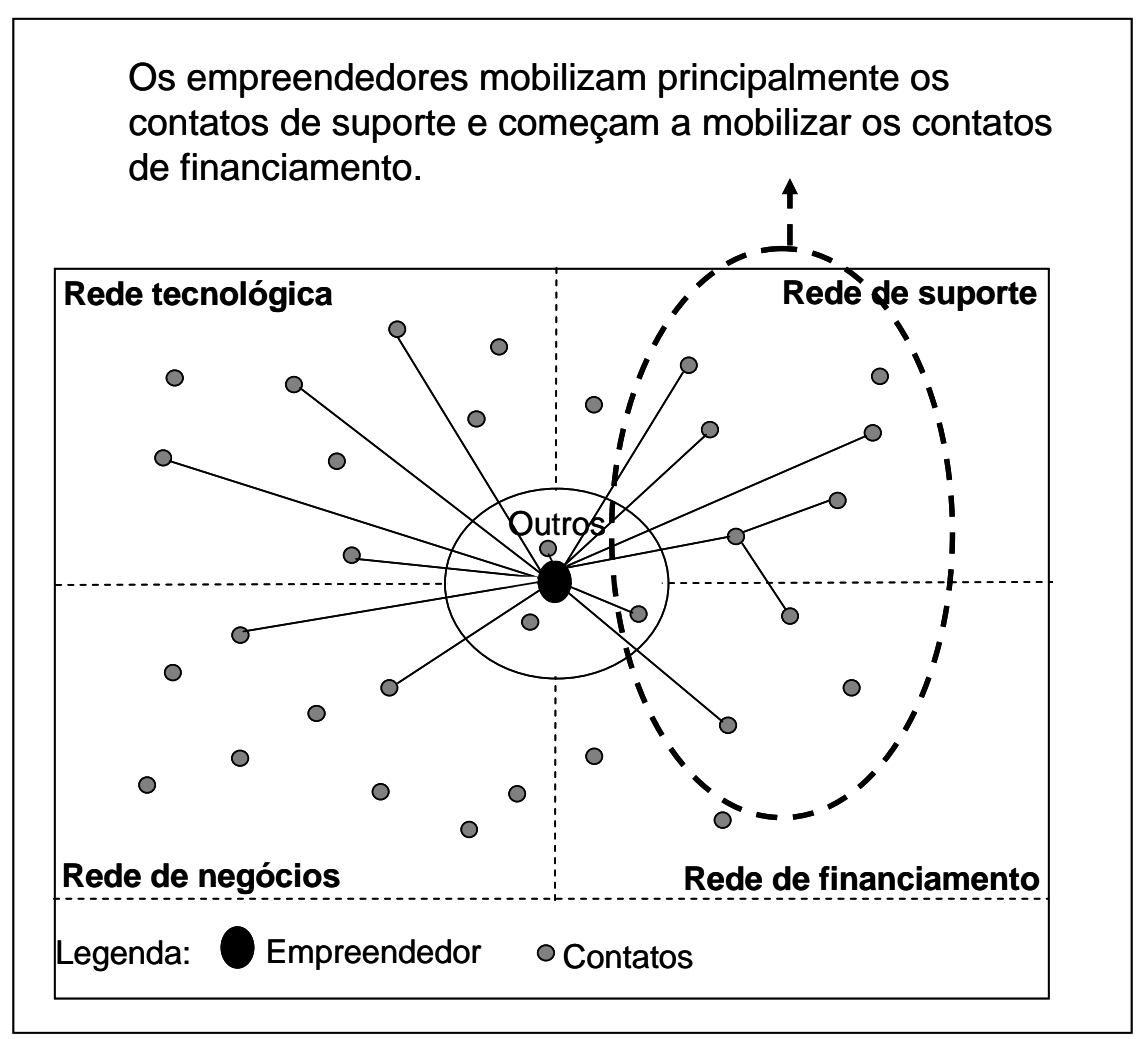

Outro aspecto importante nessa etapa é o inicio da mobilização dos contatos de financiamento. Trata-se principalmente das agências governamentais, como a FINEP (Financiadora de Estudos e Projetos) e o CNPq (Conselho Nacional de Desenvolvimento Científico e Tecnológico). Apesar da ajuda financeira dessas agências, muitos empreendedores ainda dependem de recursos próprios ou do financiamento de parentes - este é um dos fatores que explicam a presença de familiares na rede mobilizada nessa etapa. Os contatos de negócio, assim como foi o caso durante a etapa de iniciação, são poucos mobilizados nessa etapa de preparação.

\subsection{CAPITAL SOCIAL EMPREENDEDOR NA ETAPA LANÇAMENTO}

Nessa etapa do processo de criação da empresa, denominada lançamento, ocorrem atividades como o desenvolvimento do produto, o registro legal da empresa e o início das atividades de comercialização. Se, durante a etapa de iniciação, a rede mobilizada foi principalmente a tecnológica e, na etapa de preparação, os contatos de suporte e de financiamento também foram mobilizados, nessa etapa o 
capital social empreendedor torna-se ainda mais diversificado, com o crescimento da mobilização dos contatos de negócio. A figura 4 ilustra o capital social mobilizado nessa etapa.

Figura 4 - Ilustração do capital social empreendedor na etapa lançamento

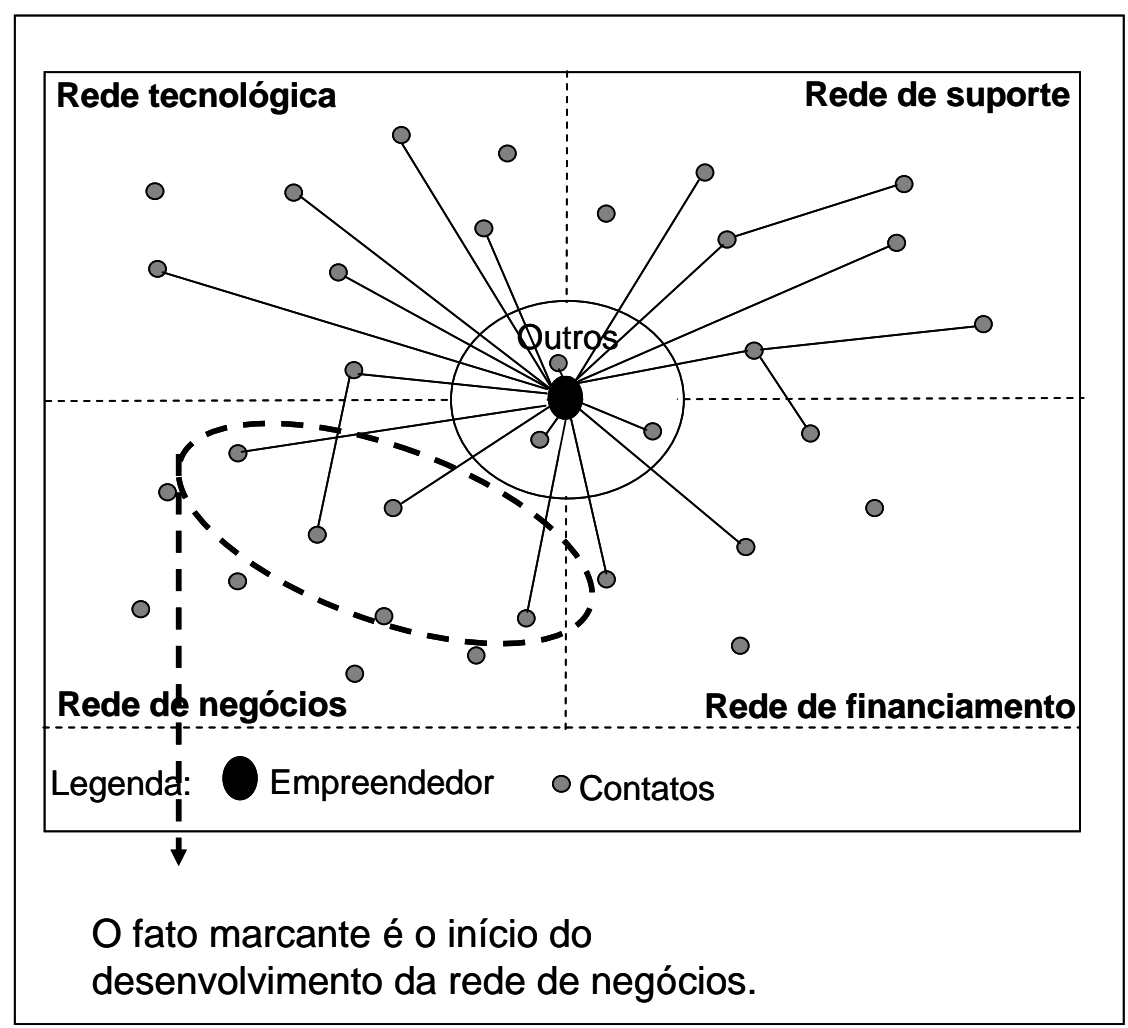

Para alguns empreendedores universitários, foi somente nessa etapa que eles começaram a mobilizar contatos de negócios. São empreendedores que passaram as duas primeiras etapas do processo de criação e todo o desenvolvimento do produto praticamente fechados em si e só quando precisaram comercializar o produto é que foram procurar clientes.

Estes empreendedores, que retardam a mobilização dos contatos de negócio, encontram dificuldades adicionais no processo de criação, quando comparados aos empreendedores que desde o início envolveram clientes em potencial ou outros contatos de negócios em suas atividades. O primeiro grupo, muitas vezes, chega ao mercado com um produto inadequado às necessidades de clientes e de consumidores em potencial, pois em momento algum envolveram clientes na reflexão e desenvolvimento do produto. Em consequência, encontram dificuldades para realizar suas primeiras vendas. 
Caminho diferente seguiu a empresa Sensores, que faz parte dos casos de empreendedores que, desde o início, envolveram clientes nas atividades do processo de criação. A ideia de negócio surgiu da demanda de um cliente em potencial, que foi parceiro da empresa durante o desenvolvimento do produto, inclusive ajudando a financiar o seu desenvolvimento e servindo como campo de teste do protótipo. Quando chegou o momento da comercialização, a empresa Sensores não encontrou nenhuma dificuldade para realizar sua primeira venda, pois o seu primeiro cliente foi o parceiro comercial que a acompanhou desde a etapa de iniciação.

\subsection{CAPITAL SOCIAL EMPREENDEDOR NA ETAPA CONSOLIDAÇÃO}

Nessa etapa, assim como na etapa lançamento, o capital social empreendedor já está diversificado. Contatos da rede tecnológica, de suporte e de financiamento e de negócios e também familiares ou amigos são mobilizados. $O$ nível de utilização destes contatos é que muda em relação à etapa precedente.

Como indicado na figura 5, abaixo, ocorre na etapa consolidação um crescimento da mobilização dos contatos de negócio. No sentido contrário, as redes de suporte, tecnológica e a família são menos mobilizadas nessa etapa que na etapa precedente. A mobilização da rede de financiamento continua no mesmo nível que na etapa lançamento, com uma pequena mudança: alguns empreendedores começam a diversificar suas fontes de recursos e a utilizar, entre outros, os anjos financeiros. 
Figura 5 - Ilustração do capital social empreendedor na etapa consolidação

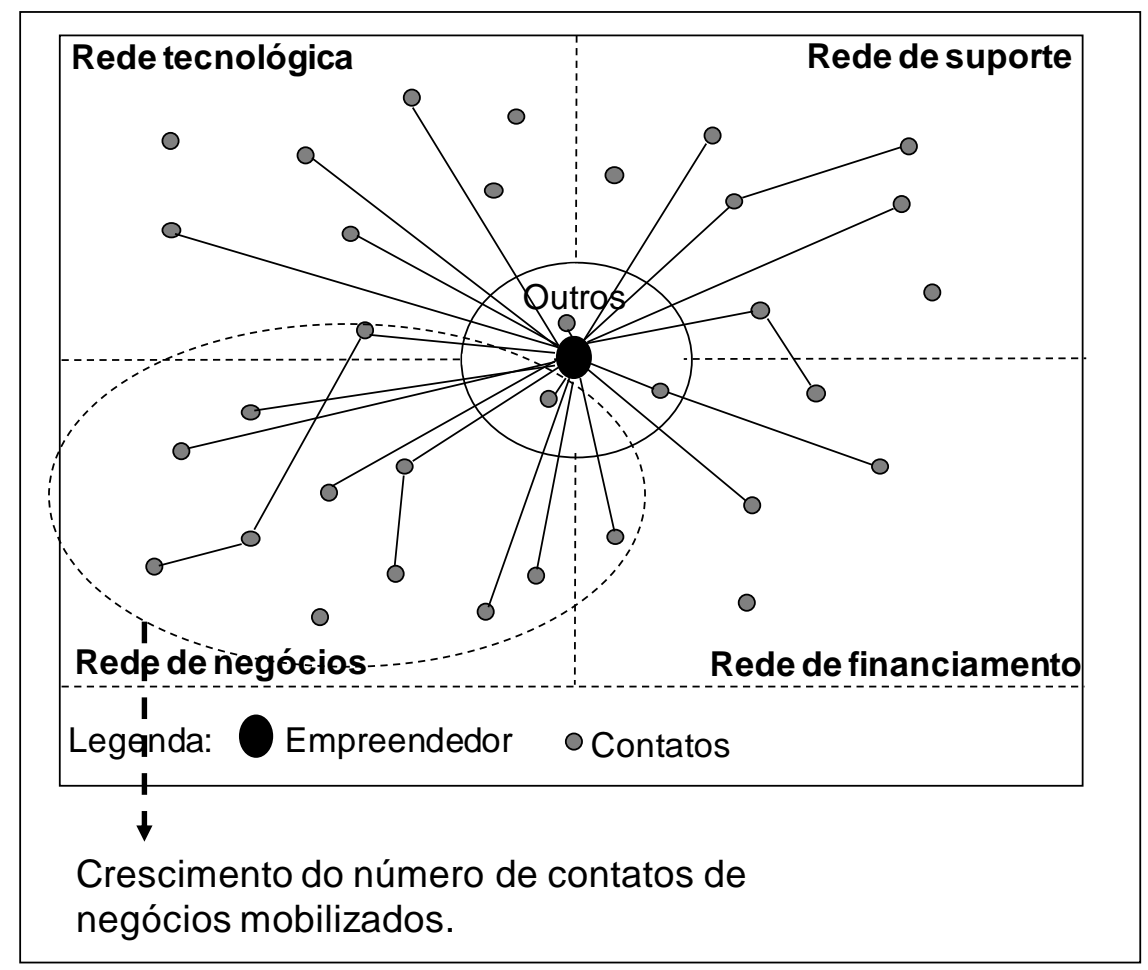

Essas mudanças nas características do capital social empreendedor durante a etapa de consolidação coincidem com as mudanças significativas pelas quais os spin-offs passam nesse estágio de seu desenvolvimento. Em primeiro lugar, elas vivem um momento de maior inserção no mercado - buscam consolidar sua parte comercial e gerar novos negócios. Em segundo lugar, a etapa de consolidação coincide, na maior parte dos casos, com o fim do processo de incubação. Voluntariamente ou não, as empresas nascentes deixam a incubadora universitária e se instalam em uma área fora do ambiente universitário. Em consequência, os empreendedores deixam de estar imersos em um ambiente cercado por contatos tecnológicos (da universidade) e de suporte (da incubadora).

\section{CONSIDERAÇÕES FINAIS}

A figura 6, abaixo, ilustra a evolução do capital social empreendedor ao longo das etapas do processo de criação. Na etapa iniciação, o capital social mobilizado é essencialmente tecnológico. Na etapa preparação, os empreendedores mobilizam principalmente contatos de suporte e começam a mobilizar os contatos de financiamento. Na etapa lançamento, o capital social empreendedor é mais 
diversificado: contatos tecnológicos, de suporte, de financiamento e de negócios são mobilizados. Finalmente, na etapa consolidação, foi constatado um crescimento da mobilização da rede de negócios.

Figura 6 - Evolução do capital social empreendedor ao longo das etapas do processo de criação

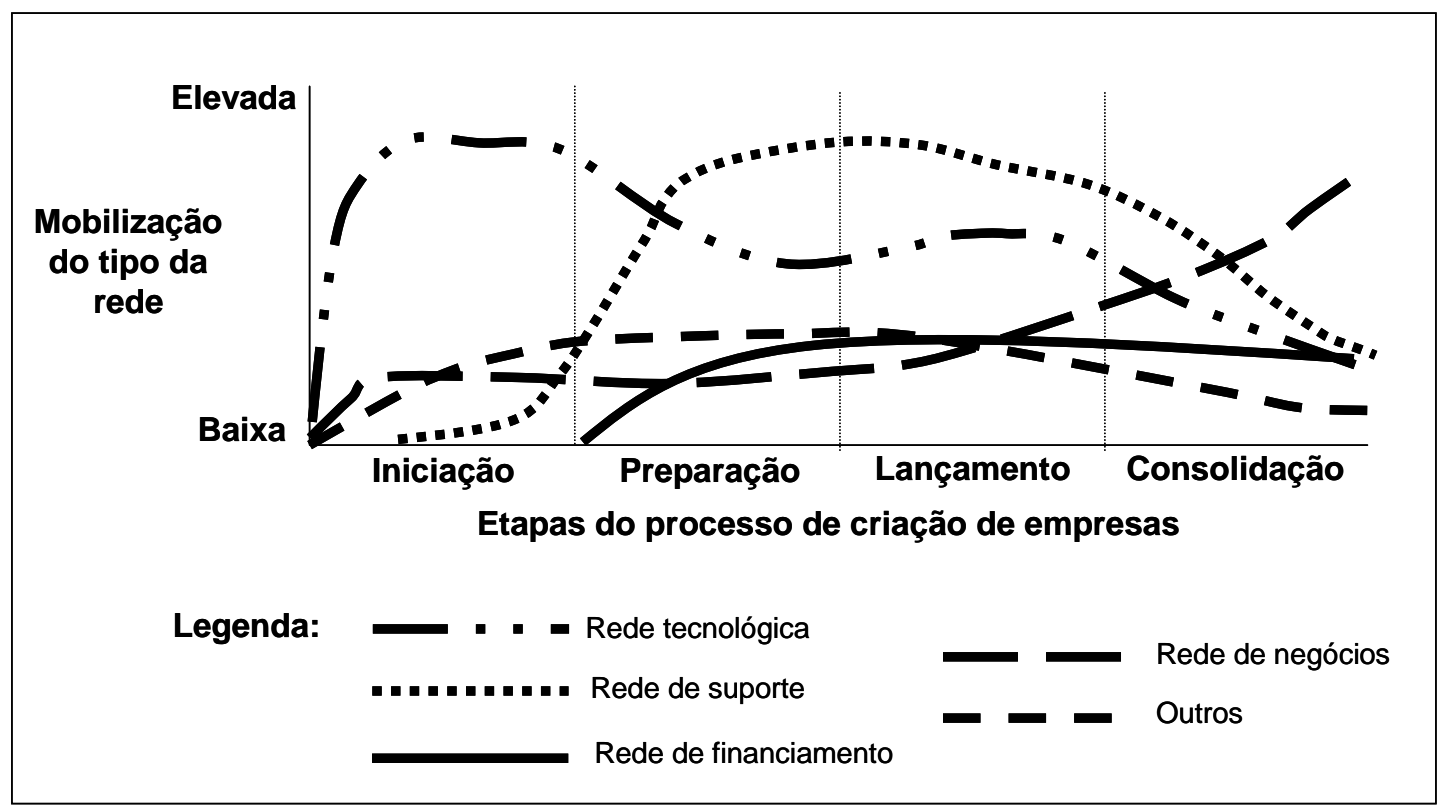

O capita social empreendedor passa de uma rede majoritariamente tecnológica a uma rede mais diversificada, que inclui todas as categorias de rede e uma composição contando proporcionalmente cada vez mais contatos de negócio. Essas mudanças reafirmam os resultados de outras pesquisas, que haviam mostrado o caráter dinâmico, progressivo e evolutivo do capital social dos empreendedores ao longo do processo de criação de uma nova empresa (JOHANNISSON, 1998; HANSEN, 2000; GREVE ; JANE, 2003; LECHNER; DOWLING, 2003; PEREZ; SANCHEZ, 2003; SCHUTJENS; STAM, 2003; NEERGAARD; MADSEN, 2004). A particularidade da pesquisa apresentada nesse artigo reside em mostrar essa evolução por etapas, detalhando sua progressão.

Fato importante a notar é a importância dos empreendedores anteciparem a mobilização dos contatos de negócio. Como mostrado na seção precedente, de apresentação de resultados, é principalmente na etapa de lançamentos que os empreendedores universitários começam a mobilizar esse tipo de contato. Os empreendedores que anteciparam esse tipo de relacionamento, mobilizando uma 
rede de negócios desde a etapa de iniciação, obtiveram vantagens em aspectos como a possibilidade de obter informações de mercado diretamente de um consumidor ou cliente em potencial. Para que esse tipo de relação se multiplique, as universidades e suas incubadoras poderiam favorecer, desde os primeiros dias de vida da empresa nascente, a interação de seus spin-offs com contatos de negócios.

Entre os diferentes tipos de rede, a rede de negócios é justamente aquela mais difícil para os empreendedores desenvolverem e onde as incubadoras encontram maior dificuldade em oferecer mecanismos que, efetivamente, ajudem os empreendedores nesse desenvolvimento. Nesse sentido, seriam importantes novas pesquisas, que explorassem e desenvolvessem mecanismos de apoio à criação de contatos de negócios pelos empreendedores universitários, ou os fatores que podem favorecer tal desenvolvimento. Por exemplo, os fatores de localização das incubadoras (BARQUETTE, 2002) ou os serviços que elas oferecem (RAUPP; BEUREN, 2009) parecem ser fatores que podem colaborar para esse processo.

Um dos limites da pesquisa apresentado nesse artigo é que coleta de dados foi feita com apenas dois tipos de contatos da rede: os empreendedores e os gerentes de incubadoras. Uma nova pesquisa poderia coletar dados também com outros tipos de contatos das redes dos empreendedores universitários e, dessa forma, alcançar uma visão mais completa dinâmica do capital social. Outro limite da pesquisa reside no fato que não foi possível coletar dados de forma longitudinal, em diferentes momentos da evolução do capital social. Essa evolução foi, nesse artigo, reconstituída com os relatos dos empreendedores e outros dados coletados. Uma pesquisa longitudinal e não em retrospectiva como essa pode descobrir novos e importantes elementos que ajudem na compreensão da evolução do capital social.

\section{REFERÊNCIAS}

ADLER, P. S; KWON, S.-W. Social capital: prospects for a new concept. Academy of Management Review, v. 27, n. 1, p. 17-40, 2002.

ALDRICH, H. Organizations evolving. London: Sage Publications, 1999.

ALDRICH, H., ZIMMER, C. Entrepreneurship through social networks. In: SEXTON, D. L; SMILOR, R. W. (Eds), The Art and science of entrepreneurship. Cambridge: Ballinger, p. 3-23, 1986. 
ALDRICH, H; CARTER, N. M. Social networks. In GARTNER, W. B. et al. (Eds). Handbook of entrepreneurial dynamics: the process of business creation Thousand Oaks: Sage, p. 324-335, 2004.

ALDRICH, H; ROSEN, B; WOODWARD, W. The impact of social networks on business foundings and profit: a longitudinal study. In: Churchill, N. C. e outros (Eds). Frontiers of Entrepreneurship Research 1987. Wellesley: Babson College, p. 154168, 1987.

BARQUETTE, S. Fatores de localização de incubadoras e empreendimentos de alta tecnologia. Revista de Administração de Empresas, v. 42, n. 3, p. 101-113, 2002.

BATJARGAL, B. Social capital and entrepreneurial performance in Russia: a longitudinal study. Organization Studies, v. 24, n. 4, p. 535-556, 2003.

BHAVE, M. P. A process model of entrepreneurial venture creation. Journal of Business Venturing, v. 9, n. 3, p. 223-242, 1994.

BIRLEY, S. The role of networks in the entrepreneurial process. Journal of Business Venturing, v. 1, n. 1, p. 107-117, 1985.

BORGES, C. Os spin-offs universitários e seus componentes principais. In: GIMENEZ, F.A.P. ; FERREIRA, J.M.; RAMOS, S.C. (Orgs.). Empreendedorismo e estratégia de empresas de pequeno porte. Curitiba: Champagnat, p. 9-16, 2010.

BORGES, C; FILION, L. J; SIMARD, G. Estudo comparativo entre o processo de criação de empresas tecnológicas e o de empresas tradicionais. Revista de Administração e Inovação, v. 7, n. 2, p. 3-21, 2010.

BOURDIEU, P. Le capital social: notes provisoires. Actes de la recherche en Sciences Sociales, v. 3, n. 3, p. 2-3, 1980.

BOURDIEU, P. The forms of capital. In: RICHARDSON, J. G. (Ed). Handbook of theory and research for the sociology of education. Westport: Greenwood Press, p. 241-258, 1986.

BRUYAT, C; JULIEN, P.A. Defining the field of research in entrepreneurship. Journal of Business Venturing, v. 16, n. 2, p. 165-180, 2001.

BURT, R. S. Structural holes: the social structure of competition. Cambridge: Harvard University Press, 1992. 
CARTER, N. M; GARTNER, W. B; REYNOLDS, P. D. Exploring start-up event sequences. Journal of Business Venturing, v. 11, n. 3, p. 151-166, 1996.

CLARYSSE, B. et al. Spinning out new ventures: a typology of incubation strategies from European research institutions. Journal of Business Venturing, v. 20, n. 2, p. 183-216, 2005.

CLARYSSE, B; MORAY, N. A process study of entrepreneurial team formation: the case of a research-based spin-off. Journal of Business Venturing, v. 19, n. 1, p. 55-79, 2004.

COOPER, A. C. Networks, alliances, and entrepreneurship. In: HITT, M. et al. (Eds.). Strategic entrepreneurship: creating a new mindset. Oxford: UK Blackwell, p. 203-222, 2002.

COOPER, A. C; DAILLY, C. M. Entrepreneurial Teams. In: SEXTON, D; SMILOR, R. W. (Eds). Entrepreneurship 2000. Chicago: Upstart, p. 167-188, 1997.

DAVIDSSON, P; HONIG, B. The role of social and human capital among nascent entrepreneurs. Journal of Business Venturing, v. 18, n. 3, p. 301-331, 2003.

DI GREGORIO, D; SHANE, S. Why do some universities generate more start-ups than others?. Research Policy, v. 32, n. 2, p. 209-227, 2003.

DUBINI, P; ALDRICH, H. Personal and extended networks are central to the entrepreneurial process. Journal of Business Venturing, v. 6, n. 5, p. 305-313, 1991.

EISENHARDT, K. M. Building theories from case study research. Academy of Management Review, v. 14, n. 4, p. 532-550, 1989.

FILION, L. J. (Ed). Réaliser son projet d'entreprise. Montréal: Éditions Transcontinental, 2001.

FILION, L. J; LUC, D; FORTIN, P.-A. L'essaimage d'entreprises - Vers de nouvelles pratiques entrepreneuriales. Montreal: Les Éditions Transcontinental, 2003.

FRANKLIN, S.; WRIGHT, M. University spin-out companies: academic and surrogate entrepreneurs. In: DURING, W; OAKEY, R. P.; KIPLING, M. (Eds.). New Technology-Based Firms at the Turn of the Century. Amsterdam: Pergamon, p.35-49, 2000. 
GRANOVETTER, M. Le marché autrement : les réseaux dans l'économie. Paris: Desclée de Brouwer, 2000.

GREVE, A.; JANE, W. S. Social networks and entrepreneurship. Entrepreneurship Theory and Practice, v. 28, n 1, p. 1-22.

GRIMALDI, R.; GRANDI, A. Business incubators and new venture creation: an assessment of incubating models. Technovation, v.25, n.2, p.111-121, 2005.

HANSEN, E. L. Resource acquisition as a startup process: initial stocks of social capital and organizational foundings. In: REYNOLDS, P. D.; AUTIO, E; BRUSH,C. G.; BYGRAVE, S. MANIGART, H. J. SAPIENZA; K. G. SHAVER (Eds.). Frontiers of Entrepreneurship Research 2000. Wellesley: Babson College. 2000.

HILL, J.; McGOWAN, P.; DRUMMOND, P. The development and application of a qualitative approach to researching the marketing networks of small firm entrepreneurs. Qualitative Market Research, v. 2, n. 2, p. 71-81, 1999.

HITE, J. M. Patterns of multidimensionality among embedded network ties: a typology of relational embeddedness in emerging entrepreneurial firms. Strategic Organization, v.1, n. 1, p. 9-49, 2003.

HOANG, H.; ANTONCIC, B. Network-based research in entrepreneurship: a critical review. Journal of Business Venturing, v. 18, n. 2, 165-187, 2003.

JOHANNISSON, B. Personal networks in emerging knowledge-based firms: Spatial and functional patterns. Entrepreneurship \& Regional Development, v. 10, n. 4, p. 297-312, 1998.

JOHANNISSON, B. The dynamics of entrepreneurial networks. In REYNOLDS, P. D.; BIRLEY, S.; BUTLER, J. E.; BYGRAVE, W. D.; DAVIDSSON, P.; . GARTNER; MCDOUGALL, P. P. (Eds.). Frontiers of Entrepreneurship Research 1996, Wellesley: Babson College, 1996.

JOHANNISSON, B.; RAMIREZ-PASILLAS, M.; KARLSSON, G. The institutional embeddedness of local inter-firm networks: A leverage for business creation.

Entrepreneurship \& Regional Development, v. 14, n. 4, p. 297-315, 2002.

JULIEN, P.-A. L'entrepreneuriat au Québec - Pour une révolution tranquille entrepreneurial 1980-2005. Montreal: Les Éditions Transcontinental, 2000.

KADJI-YOUALEU, C.; FILION, L. J. . Essaimage technologique - Examen de la documentation. Cahier de recherche 2002-14, Chaire d'entrepreneuriat Rogers -J.A.-Bombardier, HEC Montréal, 2002. 
KIM, P. H.; ALDRICH, H. E. Social capital and entrepreneurship. Boston: Now, 2005.

LANGLEY, A. Strategies for theorizing from process data. Academy of Management Review, v. 24, n. 4, p. 691-710, 1999.

LAZEGA, E. . Réseaux sociaux et structures relationnelles. Paris: Presses universitaires de France, 1998.

LECHNER, C.;DOWLING, M. Firm networks: external relationships as sources for the growth and competitiveness of entrepreneurial firms. Entrepreneurship \& Regional Development, v. 15, n. 1, p. 1-26, 2003.

LEMIEUX, V.; OUIMET, M. L'analyse structurale des réseaux sociaux. Québec: Presses de l'Université Laval, 2004.

LIAO, J.; WELSCH, H. Social capital and entrepreneurial growth aspiration: A comparison of technology- and non-technology-based nascent entrepreneurs. Journal of High Technology Management Research, v. 14, n. 1, p. 149-170, 2003.

LIAO, J.; WELSCH, H. The temporal patterns of venture creation process: an exploratory study. In: BYGRAVE, W. D.; BRUSH, C.C.; DAVIDSSON, P.; FIET, J.; GREENE, P. G.; HARRISON, R. T.; LERNER, M.; MEYER, G. D.; SOHL, J.; ZACHARAKIS, A. (Eds.). Frontiers of Entrepreneurship Research 2002. Wellesley: Babson College, 2002.

LIN, N. Building a network theory of social capital. In: LIN, N.; COOK, K. S.; BURT, R. S. (Ed.). Social capital: theory and research. New York: Aldine de Gruyter, 2001a.

LIN, N. Social capital: a theory of social structure and action. Cambridge: Cambridge University Press, 2001b.

LUC, D.; SAVARY, I.; FILION, L. J. Guide sur l'essaimage d'entreprises technologiques. Cahier de recherche 2003-01, Chaire d'entrepreneuriat Rogers -J.A.-Bombardier, HEC Montréal, 2003.

MACULAN, A. M.; VINHAS, V. Q.; FARIA, R. F.; GUEDES, M. Reflexões sobre o desempenho inovador das empresas graduadas. In: SIMPÓSIO DE GESTÃO DA INOVAÇÃO TECNOLÓGICA, 22, 2002, Salvador. Anais...[s.n.t.], 2002.

MEYER, M. Academic entrepreneurs or entrepreneurial academics? Researchbased ventures and public support mechanisms. R \& D Management, v. 33, n. 2, p. 107-115, 2003. 
MILES, M. B.; HUBERMAN, A. M. Qualitative data analysis: an expanded sourcebook. 2 ed. Thousand Oaks, Calif.: Sage, 1994.

NAHAPIET, J.; GHOSHAL, S. Social capital, intellectual capital, and the organizational advantage. Academy of Management Review, v. 23, n. 2, p. 242266, 1998.

NDONZUAU, F.; PIRNAY, F.; SURLEMONT, B. A stage model of academic spin-off creation. Technovation, v. 22, n. 2, p. 281-289, 2002.

NEERGAARD, H. Networking activities in technology-based entrepreneurial teams. International Small Business Journal, v. 23, n. 3, p. 257-278, 2005.

NEERGAARD, H.;MADSEN, H. Knowledge intensive entrepreneurship in a social capital perspective. Journal of Enterprising Culture, v. 12, n. 2, p. 105-125, 2004.

NICOLAOU, N.;BIRLEY, S. Academic networks in a trichotomous categorisation of university spinouts. Journal of Business Venturing, v. 18, n.3, p. 333-359, 2003.

ORGANISATION DE COOPÉRATION ET DE DÉVELOPPEMENT ÉCONOMIQUES. Special issue on fostering high-tech spin-offs: a public strategy for Innovation. Paris: Organisation for Economic Co-operation and Development, 2001.

PATTON, M. Q. Qualitative research \& evaluation methods. 3ed. Thousand Oaks: Sage Publications, 2002.

PEREZ, M. P.; SANCHEZ, A. M. . The development of university spin-offs: early dynamics of technology transfer and networking. Technovation, v. 23, n.10, p. 823831, 2003.

PIRNAY, F. La valorisation économique des résultats de recherche universitaire par création d'activités nouvelles (spin-offs universitaires): Propostion d'un cadre procedural d'essaimage. Tese (pour le doctorat nouveau régime en Sciences de Gestion) - Université du Driot et de la Santé ,Lille 2, 2001.

PIRNAY, F.; SURLEMONT, B.; NLEMVO, F. Toward a typology of university spinoffs. Small Business Economics, v. 21, n. 4, p. 355-369, 2003.

RADOSEVICH, R. A model for entrepreneurial spin-offs from public technology sources. International Journal of Technology Management, v. 10, n. 7-8, p. 879893, 1995. 
RAUPP, F. M.;BEUREN, I. M. Programas oferecidos pelas incubadoras brasileiras às empresas incubadas. Revista de Administração e Inovação, v. 6, n. 1, p. 83107. 2009.

REYNOLDS, P.; MILLER, B. New firm gestation: conception, birth, and implications for esearch. Journal of Business Venturing, v. 7, n.5, p. 405-417, 1992.

SCHUTJENS, V.; STAM, E. The evolution and nature of young firm networks: A longitudinal perspective. Small Business Economics, v. 21, n. 2, p.115-134, 2003.

SCOTT, J. Social network analysis: a handbook. London: Sage, 1991.

SHANE, S. Academic entrepreneurship: university spinoffs and wealth creation. Cheltenham: Elgar, 2004.

STRAUSS, A. L.; CORBIN, J. M. Basics of qualitative research: techniques and procedures for developing grounded theory. Thousand Oaks: Sage Publications, 1998.

TESFAYE, B. Patterns of Formation and Development of High-Technology Entrepreneurs. In JONES-EVANS, D.; KLOFSTEN, M. (Eds.). Technology, Innovation and Enterprise - The European Experience. London: Macmillan Press, p. 61-106, 1997.

UZZI, B. The sources and consequences of embeddedness for the economic performance of organizations: the network effect. American Sociological Review, v. 61, n. 4, p. 674-698, 1996.

VALE, G.; GUIMARAES, L. Redes sociais na criação e mortalidade de empresas. Revista de Administração de Empresas, v. 50, n. 3, p. 325-337, 2010.

VAN DE VEN, A. H.; POOLE, M. S. Explaining development and change in organizations. Academy of Management Review, v. 20, n. 3, p. 510-540, 1995.

VAN DER GAAG, M.; SNIJDERS, T. A. B. Proposal for the measurement of individual social capital. In: FLAP, H. D.; VOLKER, B. (Eds.). Creation and returns of social capital: a new research program. London: Routledge, p. 199-218, 2004.

VAN DER GAAG, M.; SNIJDERS, T. A. B. The Resource Generator: social capital quantification with concrete items. Social Networks, v. 27, n. 1, p. 1-29, 2005.

VERSIANI, A.; GUIMARAES, L. Creation of technologically-based firms in Brazil: the influence of incubators on the set-up of new business. Revista Eletrônica de

Administração, v. 12, n.3, p. 1-23, 2006. 
VERSIANI, A.; GUIMARAES, L. Aprendendo a estruturar um novo negocio - o papel das incubadoras na constituição das pequenas empresas de base tecnológica. In: ENCONTRO DA ASSOCIAÇÃO NACIONAL DE PÓS-GRADUAÇÃO E PESQUISA EM ADMINISTRAÇÃO, 27., 2003, Atibaia. Anais... Atibaia [s.n.t.], 2003.

VESPER, K. H. New venture strategies. Englewood Cliffs: Prentice-Hall, 1990.

VOHORA, A.; WRIGHT, M.; LOCKETT, A. Critical junctures in the development of university high-tech spinout companies. Research Policy, v. 3, n. 1, p. 147, 2004.

WASSERMAN, S.; FAUST, K. Social network analysis: methods and applications. Cambridge: Cambridge University Press, 1997.

WITT, P. Entrepreneurs' networks and the success of start-ups. Entrepreneurship and Regional Development, v. 16, n. 5, p. 391-412, 2004.

WOLFFENBÜTTEL, A.; FRACASSO, E.; BIGNETTI, L. The university-firms interaction process in a university incubator: the case of the Vale do Rio dos Sinos University's incubator Revista Eletrônica de Administração, v. 10, n. 1, p. 1-19, 2004.

YIN, R. K. Case study research: design and methods. 3 ed. Thousand Oaks: Sage Publications, 2003. 